\title{
GCU
}

Glasgow Caledonian

University

University for the Common Good

\section{Assessing community perception and attitude towards flooding in the Lower Benue River Basin, Nigeria}

Unaegbu, Emmanuel U. ; Baker, Keith

Published in:

Journal of Earth Science and Climatic Change

DOI:

$10.4172 / 2157-7617.1000206$

Publication date:

2014

Document Version

Publisher's PDF, also known as Version of record

Link to publication in ResearchOnline

Citation for published version (Harvard):

Unaegbu, EU \& Baker, K 2014, 'Assessing community perception and attitude towards flooding in the Lower Benue River Basin, Nigeria', Journal of Earth Science and Climatic Change, vol. 5, no. 206.

https://doi.org/10.4172/2157-7617.1000206

\section{General rights}

Copyright and moral rights for the publications made accessible in the public portal are retained by the authors and/or other copyright owners and it is a condition of accessing publications that users recognise and abide by the legal requirements associated with these rights.

Take down policy

If you believe that this document breaches copyright please view our takedown policy at https://edshare.gcu.ac.uk/id/eprint/5179 for details of how to contact us. 


\section{Assessing Community Perception and Attitude towards Flooding in the Lower Benue River Basin, Nigeria}

Emmanuel U. Unaegbu* and Baker $\mathrm{K}$

School of Engineering and Built Environment, Glasgow Caledonian University, UK

*Corresponding author: Emmanuel U. Unaegbu, School of Engineering and Built Environment, Glasgow Caledonian University, UK, Tel: +2348037502850; E-mail: emmaunaegbu_dom@yahoo.com

Rec date: Mar 28, 2014, Acc date: May 13, 2014, Pub date: July 28, 2014

Copyright: (c) 2014 Unaegbu EU, et al. This is an open-access article distributed under the terms of the Creative Commons Attribution License, which permits unrestricted use, distribution, and reproduction in any medium, provided the original author and source are credited.

\begin{abstract}
In the Lower Benue River Basin, the majority of the population derives their livelihood from subsistent farming and fishing. With climate change expected to result in increased flooding, the impacts on these poor rural farmers will be significant and since adaptation is not cheap, prioritizing responses by sectors becomes essential. Such an analysis can bring to the fore the sectors that are most affected and by implication sectors of importance to the community. Two communities: Wadata and Anyim were selected for survey. Health, housing, agriculture, economic activities, transportation and water are the sectors evaluated. Results reveal agriculture; housing; and economic activities as the worst affected sectors. In furtherance, we argue that prioritization of adaptation by sectors can provide immediate relief for victims. Vulnerability in the region is exacerbated by 'late' and 'historic incorrect' environmental change communication. Household insurance is non-existent and somewhat non-customary thus, financial adjustments are presumably made with household savings or assets disposal.
\end{abstract}

Keywords: Flooding; Lower Benue River Basin; Nigeria; Perception; Communication; Adaptation prioritization

\section{Introduction}

For thousands of years people have been involved in developing ways to protect themselves against the adverse effect of flooding. For example, China city walls were built to defend it against flooding over 4000 years ago [1]. Today, most countries of the world suffer some kind of flooding and Nigeria is no different. Since the 1950 from which flooding data has been available for the country, nine of the top ten natural disasters (in terms of cost and people affected) are flooding events [2]. As Ibem [3] commented; flooding can easily be tagged as the most extensive and expensive natural disaster in Nigeria. The flooding events of September 2012 go down as the worst in Nigeria's recorded history, accounting for hundreds of fatalities and millions of displaced persons nationwide [4]. In Benue state 'the food basket of the nation' alone, tens of thousands of people were displaced across 14 communities. With changing climatic conditions, such flooding events are not only likely to reoccur but with impacts and damages that are more devastating. Thus there is need for systems efficiency and perception studies.

According to Few [5], flooding has the potential to cause social, economic and environmental damage. Thus flooding is capable of disrupting sustainable development initiatives. Flood is a major factor preventing development and improved quality of life for many African poor communities [6]. In Nigeria, flooding events are influenced by a range of factors including: the overflow of the numerous rivers that transverse the country, unprecedented rainfall amounts and intensity, dam breaks and levee failure, the unavailability and/or insufficient drainage systems and the underutilization of dams in some parts of the country $[3,6,7]$. In some locations, illegal dumping of refuse along water ways and drainages has influenced flooding events in urban cities [8].
Flooding in the LBRB region has been attributed to river and flash flood events leading to river overflow [9] and rainfall intensity [10]. With a lot of communities located by the River Benue bank and the region supplying a huge quantity of food consumed in Nigeria, finding long-term solutions to the incessant flooding within the LBRB needs to be systematic and strategic. Several studies have looked at the flooding situation in Nigeria [3,7-12] but studies on flood perception, communication and adjustment in Nigeria have received very little attention and a great deal of insight can be derived from how people react to changes caused by flooding. Perception and attitude of people may reveal the urgency with which the problem needs to be tackled and which sectors are most vulnerable. Again, development of strategic policies and implementation needs to rest on resident's perception and attitude towards flooding. According to Ologunorisa and Adeyemo [12], perception studies are essential for responsible planning of flood alleviation schemes and development.

Upon this theoretical foundation, the study explores the perception of impacts on selected sectors/topics - health, housing, agriculture, transportation and water. Based on qualitative data obtained from the administration of questionnaires, evaluations of perceived impact extent on selected sectors were analysed. Such an evaluation will help identify sectors of priority to locals. This is in line with the works of Brooks et al. [13] and Roberts [14]. Determining the impacts of importance to a community provides the mechanism for prioritizing adaptation options [14]. Understanding the effects of environmental change on different sectors is critical for the development of a strategic action plan. The way people react to environmental change is determined to some extent by their level of knowledge and/or quality of information in their possession. As Van Aalst et al. [15] posited; timely dissemination of environmental change information creates opportunity for risk reduction. To this end, environmental change information communication process between survey participants and relevant government agencies is evaluated. In addition, insurance 
Citation: Unaegbu EU and Baker K (2014) Assessing Community Perception and Attitude towards Flooding in the Lower Benue River Basin,

Page 2 of 7

policy holding as a means of financial adjustment among households is also assessed.

\section{Study Area}

The Lower Benue River Basin (LBRB) is one of the twelve river basins in Nigeria defined by the Decree No. 35 of 1987, signed into law by the former Head of State General I.B. Babangida. The LBRB comprises the whole of Benue, Plateau and Nasarawa states. It is defined as 'the Benue River basin downstream of the Faro-Benue confluence' [16]. Covering an area of $90,554 \mathrm{~km}^{2}$, it is just under $10 \%$ of the total area of Nigeria. It has a population of 9.7 million people and a growth rate of 3\% (National Population Commission (NPC), 2006). Rain-fed agriculture is the main economy activity in the basin. Temperature ranges from $13^{\circ} \mathrm{C}$ to $37^{\circ} \mathrm{C}$ with annual rainfall of between $1100-1600 \mathrm{~mm}$. Rainy seasons within the LBRB occur between May and October causing yearly seasonal drought between November and
April. $80 \%$ of the annual rainfall occurs between June and August. The LBRB lies within the middle belt zone of Nigeria which is part of the 'derived savannah' located between the tropical rain forest of the south and the Sahel savannah of the North [17]. The basin boasts of favourable climatic and soil conditions making it good for growing almost all types of crops grown in the country and its rivers accommodate over 128 different species of fish [16]. There are potentially 51 sites suitable for locating small-scale hydropower schemes along the Benue River [18]. These dams can act as storage facilities for the excess water flowing through Benue River for irrigation purposes. The basin is home to over 40 ethnic groups suggesting a huge diversity in cultures, beliefs and practices. Resource based conflicts are a common occurrence in many parts of the region. Such violent conflicts are usually between sedentary farmers and nomadic migrants from the North seeking greener pastures for their livestock. Figure 1 highlights the location of the LBRB on the map of Nigeria.

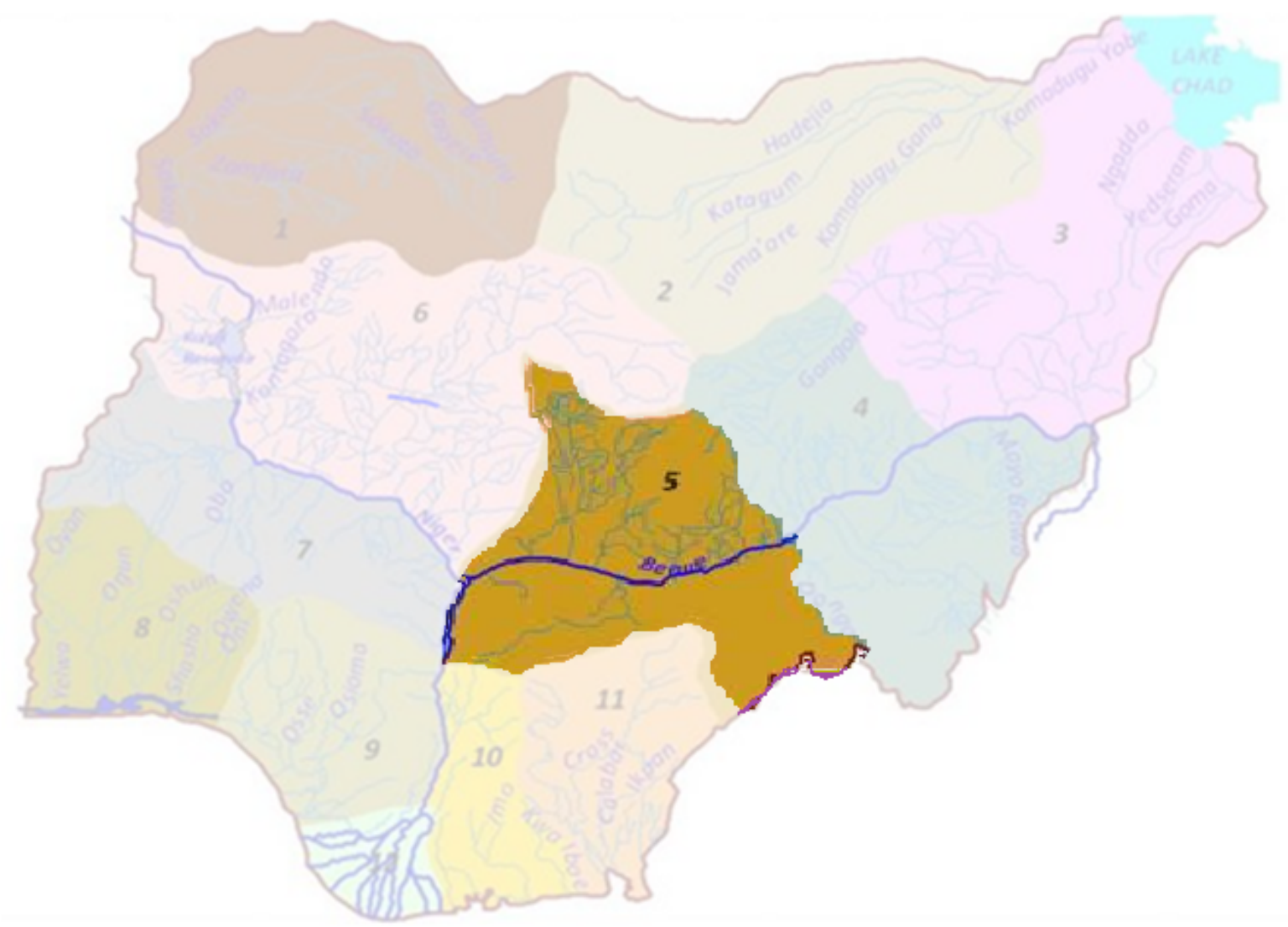

Figure 1: Map of Nigeria Highlighting the Lower Benue River Basin

\section{Methods}

The study used a questionnaire that was piloted on a small number of people in the LBRB prior to commencement. The questionnaires were administrated in the form of a semi-structured interview which took about 15-20 minutes on the average.

\section{Data collection}

The detailed questionnaire collected socio-economic and demographic characteristics of respondents, their perception of flooding impacts and adjustment systems. This included data on awareness of impending flooding, assessment of government agencies in dealing with the flooding, communication processes, and available adjustment systems (insurance). Two field assistants were recruited to 
Page 3 of 7

act as interpreters/mediators between the researcher and the natives and to assist in translating questions and when necessary explained the purpose of the research.

Given the size of the LBRB, the time and financial implications for carrying out a complete study is also impossible. Thus based on a multi-stage selection process, two study communities were chosen Wadata in Makurdi LGA and Anyim in Logo LGA. Selection is based on the literature review (including reports in local newspapers), recruited field assistant's knowledge, general geography of the areas and areas known for repeated violent communal unrests were avoided. The target participants for the study were household heads but some participants were selected by virtue of their position in the community. This was valuable as such individuals possess in-depth knowledge of events affecting their communities. A copy of the questionnaire used for the study is in the appendix section.

\section{Major Findings and Discussion}

\section{Socio-economic and demographic characteristics of survey participants}

Findings from the research show that most of the respondents 113 (67\%) were married whilst 43 (25\%) were single. This correlates with the fact that $91 \%$ of the respondents were 25 years or over and as Bigombe and Khadiagala [19] posited, average age at marriage in Nigeria is 24 years. Widowed and divorced respondents accounted for $11(7 \%)$ and 2 (1\%) respectively. Analysis of the data suggests households with both partners suffering the impacts of losses and difficulties in making adjustments as those with one surviving partner. Future studies can be carried out to provide a scientific basis for adjustment for households with both partners or otherwise.

Only $27(16 \%)$ of respondents had tertiary education while a notable 47 (28\%) had no formal education (Table 1). $84 \%$ of respondents had secondary qualification or lower which is likely to account for the low income earning in the area. According to UNISDR [20], education develops a resilient population by limiting the economic, social and cultural impacts of disasters including environmental changes. Therefore one can say that the adaptive capacity and resilience in the survey communities are limited. This is supported by the assumption that low educational status means low remunerating employment and as such inadequate adjustment capacity. As Walker et al. [21] posited; financial resources act as a 'buffer' to limit impacts.

The type of occupation in the region-predominantly household farming-also underscores the serious economic and social deprivation common in rural communities. This aligns with the works of Adger et al. [22] who posited the educational levels have strong correlation with poverty and livelihood in a society. The study communities consist of large portion of low income earners. The occupation of majority 69 (41\%) of respondents is subsistent farming. 25 (15\%) were civil servants while $19(11 \%)$ were traders. Students and housewives accounted for 17 (10\%) of the respondents each. A mere 8 (5\%) of the respondents were unemployed-mostly fresh graduate in search of jobs while $14(8 \%)$ of the respondents made their livelihood from other sources such as skilled and unskilled artisans, 'okada' (commercial motorcycle) riding, craftsmanship etc. The distribution of socioeconomic status of participants makes visible the absence of formal establishments in the area.

\begin{tabular}{|c|c|c|}
\hline $\begin{array}{l}\text { Socio-economic and demographic } \\
\text { characteristics }\end{array}$ & $\begin{array}{l}\text { Frequency } \\
(\mathrm{n}=169)\end{array}$ & $\begin{array}{l}\text { Percentag } \\
\text { e }\end{array}$ \\
\hline \multicolumn{3}{|l|}{ Age } \\
\hline $18-24$ & 15 & 9 \\
\hline $25-34$ & 32 & 19 \\
\hline $35-44$ & 45 & 27 \\
\hline $45-54$ & 36 & 21 \\
\hline $55-64$ & 27 & 16 \\
\hline 65 and above & 14 & 8 \\
\hline \multicolumn{3}{|l|}{ Gender } \\
\hline Male & 112 & 66 \\
\hline Female & 57 & 34 \\
\hline \multicolumn{3}{|l|}{ Highest educational qualification } \\
\hline Primary & 30 & 18 \\
\hline Secondary & 65 & 38 \\
\hline Tertiary & 27 & 16 \\
\hline No formal education & 47 & 28 \\
\hline \multicolumn{3}{|l|}{ Occupation } \\
\hline Civil servant & 25 & 15 \\
\hline Farmer & 69 & 41 \\
\hline Housewife & 17 & 10 \\
\hline Trader & 19 & 11 \\
\hline Student & 17 & 10 \\
\hline Unemployed & 8 & 5 \\
\hline Others & 14 & 8 \\
\hline
\end{tabular}

Table 1: Socio-economic and demographic characteristics of respondents

Longer residency in an area provides those residents with a better knowledge of local conditions, and thus it was necessary to consider the duration of residency of respondents. Over one-third 59 (35\%) of the respondents have lived in the survey communities for over 35 years. $38(22 \%)$ and $35(21 \%)$ of the respondents had lived in the communities between 26-35 years and 5-15 years respectively. Another 29 (17\%) have been living in the communities between 16-25 years while those who have lived in the survey communities just under 5 years accounted for only $8(5 \%)$ of the respondents. This statistic provides credibility for responses as most (95\%) of respondents have lived in the area for over five years.

\section{General awareness of flooding disasters}

The government mainly disseminates information via television and radio announcement. At community levels, traditional town criers are used to disseminate information. Based on this mode of communication, most respondents $(123,73 \%)$ had knowledge of the 
impending flood, and heard about it from at least one official medium (television, radio, town crier) whilst only 46 (27\%) of respondents woke up to the flooding with no prior information. Even with such a large proportion of respondents acknowledging that they had received information about the flooding, only 48 (28\%) moved away from the area to homes of relatives and friends while others went to the camps provided by government agencies. Of the $121(72 \%)$ that did not relocate, 47 (39\%) indicated that they got the information late and could not do much in terms of gathering their family and salvaging what they could before the flooding. Others $(6 \%)$ indicated that previous inaccurate warnings impeded their relocation as they had no reason to trust the information they had. This brings to the fore perceptions towards warning information and suggests a significant disconnect between victims and environmental monitoring and emergency agencies in the country. As Van Aalst et al. [15] commented; environmental change information communication needs to be of high priority when investing in risk reduction. Such weaknesses as highlighted by participants on the part of relevant government agencies undermine any action (relief and compensation) taken after a disaster. In furtherance, there is need to educate the people that monitoring of weather systems can sometimes produce inaccurate results but does not mean that information should be disregarded. In essence, they need to treat weather information independent of past warnings. More importantly, there is need for continuous and accurate monitoring of the weather systems in such a way that change information are broadcasted immediately and accurately to limit risks.

Though flooding in the LBRB is not new, most 123 (73\%) of respondents indicated that flooding of such magnitude as that of September 2012 had not been witnessed by them whilst $46(27 \%)$ indicated otherwise. $84(50 \%)$ of the respondents were of the opinion that future reoccurrence is possible, 75 (44\%) said they 'couldn't say', and only $10(6 \%)$ indicated that they thought a reoccurrence was unlikely. However, even with such strong perceptions, many residents decided to return to the area. Participants' reasons to remain in the area varied from 'no relocation options', 'strong attachment to their homes' and/or 'their occupation'. Such attachment agrees with the works of Ologunorisa and Adeyemo [12]. The perception of strong attachment with a particular area is not only shared by residents of LBRB but also among residents even in developed nations. An example is the May 2013 tornado in Moore, Oklahoma, USA where when asked by a CNN reporter why they are rebuilding instead of moving away from the area, many residents in response said they have strong attachments with the area even though they are aware that the area is situated along what is called the 'tornado alley' [23]. The only difference is that the residents of Moore are more likely to rebuild using insurance money or strong financial support from the government but this is not the case in LBRB and as with many developing nations. After the tornado in Oklahoma, insurance claim ranged between $\$ 1.5$ billion and $\$ 2$ billion in 95,000 claims [24] in contrast, emanating for this study, there is no record of any household insurance claim in the LBRB.

To buttress occupation as a reason for residents returning to the area, a respondent specified that "I can only do my business by the river side". This is because as a fisherman he derives his livelihood from fishing and selling his catch by the river side. Similarly, a farmer as an added comment said (translated): "I have farmlands passed down to me by my father and the father before him and cannot relocate with this property (land) in addition I have planted seeds with the hope to harvest and sell them". Such statements suggest that the drive to stay in the area outweighs any relocation plan. As Barnett and Webber [25] stipulate, involuntary relocation should be a last resort to environmental change adaptation. Therefore there is need to limit risk and build resilience by increasing non-farming activities in such flood prone communities as residents are likely to return and rebuild. On the other hand, this does not mean that flooding in the LBRB has not led to community change and population drift. As one respondent said, "many of our neighbours and friends have moved out and now the community does not feel the same again". Such perceptions could lead to psychological weakness affecting inherent adaptive capacities built on community cohesion and support. The researchers also observed a number of damaged and abandoned homes laying waste in the communities during the survey, indicating possible changes in neighbourhood patterns.

\section{Perception of impacts}

Table 2 presents perceived impact levels on the assessed sectors. Of the 169 respondents in the study, most 139 (82\%) suffered losses - 45\% lost property while $39 \%$ lost farmlands. None indicated loss of life directly resulting from the flooding, however this does not rule out the possibility of deaths as a result of indirect consequences (e.g. from water-borne diseases). Participants' perception of impacts on housing, agriculture and economic activities was relatively higher for 'severe impact' as compared to health, transport and water. The relatively higher percentages suggest that stability of these sectors-housing, agriculture and economic activities are of paramount importance and basic for a meaningful level of livelihood in the community. Therefore prioritizing adaptation on these sectors can minimize impacts.

\section{Health}

Almost half $(74,48 \%)$ of respondents indicated that impacts on human health were severe, whilst 43 (25\%) of respondents indicated 'don't know'-bringing into focus the difficulty of linking a particular health problem to an environmental change. As Hajat et al. [26] commented; the complex nature of flooding events on health is responsible for poor impact assessment. Again, poor data management in the country also influences perceptions as people do not have sufficient information upon which to form an opinion. Among the notable epidemic or disease outbreak indicated by respondents are malaria, cholera, typhoid, diarrhea and skin infections. With impacts of this nature, achieving Millennium Development Goal (MDG) number six-'combat HIV/AIDS, malaria and other diseases'-becomes increasingly difficult. This aligns with the works of Mainlay and Tan [27] who posited that climate changes can limit the achievement of the MDGs. In addition, indirect psychological impacts are eminent. As Walker et al. [21] commented; psychological impacts are usually based on an individual value system. The thought of losing all one has worked for could lead to depression, and in extreme cases suicide.

\section{Housing}

The nature of houses in the communities surveyed could have influenced the overall extent of damage. In Anyim communities especially, houses are built with mud and thatch roofing. Thus with heavy flooding, many houses are washed away along with their contents. However damages were not restricted to just houses built with mud sand, household properties in houses built from bricks were also damaged. This poor quality of housing also brings to the fore the low income earning of households. Results from the survey show that majority (78\%) of respondents indicated that impacts on housing were 
Page 5 of 7

'severe', while no respondent indicated 'no impact' on housing and furniture. Such overall view demonstrates how strongly the ability to link damage to a disaster drives perception. Again, an understanding of the value of household property in the mind of residents is revealed, such that an argument can made to indicate that value system drives perception. One respondent comments as follows:
"My pain is not the fact that I lost most of my property, but the fact that I cannot get some of this items from the market again and I have come to grow attachment with them."

By 'pain' he talks about bitter emotions. People generally have connection with some of their properties and sometimes these items pose as reminders of memorable events in their lives.

\begin{tabular}{|l|l|l|l|l|l|l|l|l|l|l|l|l|l|l|}
\hline & \multicolumn{2}{l}{ Health } & \multicolumn{2}{l|}{ Housing } & \multicolumn{2}{l|}{ Agriculture } & \multicolumn{2}{l|}{ Transportation } & \multicolumn{2}{l|}{ Water and Sanitation } & \multicolumn{2}{l|}{ Economic Activities } \\
\hline & F & $\%$ & F & $\%$ & F & $\%$ & F & $\%$ & F & $\%$ & F & $\%$ \\
\hline Severe Impact & 74 & 44 & 131 & 78 & 129 & 76 & 64 & 39 & 79 & 47 & 110 & 65 \\
\hline Medium Impact & 27 & 16 & 27 & 16 & 25 & 15 & 31 & 18 & 29 & 17 & 28 & 17 \\
\hline Minimal Impact & - & - & 2 & 1 & 4 & 2 & 26 & 15 & 9 & 5 & 7 & 4 \\
\hline No Impact & 25 & 15 & - & - & - & - & 14 & 8 & 6 & 4 & 4 & 2 \\
\hline Don't Know & 43 & 25 & 9 & 5 & 11 & 7 & 34 & 20 & 46 & 27 & 20 & 12 \\
\hline Total & 169 & 100 & 169 & 100 & 169 & 100 & 169 & 100 & 169 & 100 & 169 & 100 \\
\hline
\end{tabular}

Table 2: Severity of impacts on the assessed sectors

\section{Agriculture}

129 (76\%) respondents indicated 'severe impact' and no one indicated 'no impact' to agriculture. Rainfed agriculture is the economic mainstay in the LBRB and as revealed in the survey, $41 \%$ of survey participants were farmers. Thus livelihood rests on agricultural productivity. Following the above statistics, one could suggest that source of livelihood drives perception. To further buttress the foregoing, one participant as an added comment to the questionnaire survey said:

"We depend on the products we get from our farms but because of this flooding some of us lost our entire farm. It is something we have not experienced before and we were confused about the whole thing."

Another participant in expressing his loss declared:

"For me, the impact on agriculture is the most severe because it is with what we get from our farms that we are able to feed our family with and send our children to school."

Rural agricultural financing is done with personal savings or monies borrowed from informal sources such family members, neighbours, friends and/or traditional banks but rarely from government agricultural loans which focus more on commercial agriculture financing.

\section{Economic activities}

Socio-economic dynamics is recognized as a factor that drives vulnerability $[11,21,27]$. Findings from the study indicate a high degree of poverty and low income earnings reflected in the number of participants that made a living from the informal sector. Most respondents were either subsistence farmers or artisans, which appears to explain the large proportion $110(65 \%)$ of respondents that indicated 'severe impacts' on economic activities. The feeling here is one that can be expressed as "the little we have is taken from us". Since livelihood depends on harvests, damage to farms has direct impact on economic activities.

\section{Transportation}

With over $80 \%$ of interstate travel in Nigeria done by road [28] the need to scope in transportation into the assessed sectors was necessary. In addition, when roads are damaged it becomes difficult for relief agencies to provide the needed support for victims. 64 respondents (39\%) indicated that the impact of transportation was severe in both communities, while $34(20 \%)$ of respondents said 'don't know'. This signifies low value addition and hence poor attachment to the existing (poor quality) roads in the area.

\section{Water and sanitation}

Almost half 79 (47\%) of the respondents indicated that impacts on drinking water were 'severe', while over a quarter 46 (27\%) indicated 'don't know'. Drinking water in the region is obtained from running streams, rain water harvesting, purpose dug water wells, submerged pump boreholes and state water supply systems [29]. It was observed that many residents in the survey communities sourced drinking water from running streams which are unsafe for drinking, thus the water is pretreated before consumption. This can be used to explain the relative lower impact perception on water supply in the area but does not rule out consequences. As indicated by respondents, increase in the number of diarrhea and cholera cases was recorded after the flooding.

\section{Adjustment systems}

The majority 98 (58\%) of respondents had no knowledge of insurance while for the remaining $71(42 \%)$ the case was otherwise. Even with such a significant number of respondents indicating knowledge of insurance, no respondent indicated holding an insurance policy. The likely conclusion is that household insurance is not customary and disaster (flood) insurance non-existent. With the cost of insurance indicated as the major reason ( $44 \%$ of respondents) for not holding a policy among respondents with knowledge of insurance. The cost of insurance in the country in relation to average farm income suggests that it is largely unaffordable. According to the 
National Bureau of Statistics [30] survey farming household income ranges from N40,000-N60,000 NGN (Nigerian Naira) annually. These figures suggest that the lack of insurance holding is due more to income inequalities. 20\% indicated they don't need an insurance policy; this buttresses the non-customary nature of insurance among rural households in the country. $16(22 \%)$ said they never knew they could own an insurance policy for such incidents, confirming the nonexistence of disaster insurance. However, one very interesting outcome was that no participant thought insurance as a waste of money. Therefore, it is possible to conclude that adjustments are made at household level (from savings and asset disposal) and/or with funds raised from informal sources such as family, friend or local money lenders called 'ior mba nana azor' in Tiv language.

\section{Attitude towards government communication and relief process}

Many $(103,61 \%)$ respondents indicated that the government did not do enough to communicate that flooding was likely which to them is reason for the devastating impacts. $24(14 \%)$ attested that the communication from government agencies were adequate while 42 (25\%) indicated 'don't know' and this provides a background indication of the portion of respondents that received relief items. The relief items received includes clothing, blankets, food items, toiletries, drugs temporary public shelter but no monetary compensations. A resounding $62 \%$ of the respondents did not receive any form relief from any government agency. This can be attributed to the insufficient provision of relief material; respondents not needing such aid; their lack of knowledge of alleviation measures; and/or outright decision not to accept such compensation maybe owing to dissatisfaction with the unfair manner it is been shared. This poor compensation pattern and weak relief strategy agrees with the works of Ologunorisa and Adeyemo [12]. Some respondents indicated that they received relief aid from other sources such as the Nigerian Red Cross Society (NRCS) and church missions. Even among the few (38\%) that received some relief support, the general perception is that they were unequally distributed and generally insufficient. Such perceptions can lead to conflicts or new lines of communal divide and exacerbate existing challenges.

\section{Conclusions}

Flooding in the Lower Benue River Basin destroys livelihood, limits development and perceived impacts vary from sector to sector but are largely seen as 'severe impacts'. Of the six sectors evaluated, agriculture, housing and economic activities are perceived as worst hit in relation to health, transport and water. A notable driver for this differential perception is the value system in the region, thus this makes a case for adaptation prioritization. In essence, preferentially providing adaptive solutions to the worst affected sectors is imperative for risk reduction. In line with this, adaptation strategies should be integrated with government sustainable development goals. Decisions to stay in the area despite acknowledging possible reoccurrence is influenced their occupation; strong connection with the area and no better relocation option. This indicates that the need to stay surpasses any migration plan. With provision of relief materials by government agencies largely perceived as insufficient and unjustly distributed, new lines of communal divide can arise and ultimately complicate challenges faced by victims-the destruction of existing community cohesion and support systems. In addition, there exist a significant disconnection between victims and relevant government agencies judging from the acknowledged late receipt and previous wrong environmental change information by participants. With such poor communication, the number of victims and extent of damage are exacerbated and it makes light any aftermath relief or compensation arrangements; hence emphasizes the need of proper communication for disaster risk reduction. Financial adjustment systems such as insurance are non-existent among households in the survey communities. This lack of insurance holding is due more to cost of insurance driven by income inequalities than to poor knowledge of insurance mechanism. Thus to make adjustments, households use their savings, dispose assets or raise funds from informal sectors. Finally, findings from this study implies that poor communication, weak institutional support system, household-based adjustment exacerbates impacts of flooding in rural communities and there need to be a comprehensive national flood disaster action plan in Nigeria.

For future studies, a study that investigates existing adaptation strategies in rural communities is necessary as this will aid the development and implementation scientific-based strategies. Also studies to provide a scientific basis for the popular notion that household with both spouses are more likely to adjust to impacts as compared to household with only one partner should be carried out to determine the efficacy of such a notion though this study slightly indicates otherwise. An extensive study involving more communities can be carried out to provide a more generalized perception in the region.

\section{References}

1. Qingzhou W (1989) The protection of China's ancient cities from flood damages. Journal of Disasters 13: 193-227.

2. EM-DAT (2013), Disaster profiles, The OFDA/Centre for research on the epidemiology of disasters - CRED international disaster database, Université Catholique de Louvain, Brussels, Belgium.

3. Ibem EO (2011) Challenges of disaster vulnerability reduction in Lagos Megacity Area, Nigeria. Disaster Prev Manage 20: 27-40.

4. NEMA (2012) Flood: more than 25, 000 displaced in Benue as many communities remain adamant.

5. Few R (2003) Flooding, vulnerability and coping strategies: Local responses to a global threats. Prog Dev Stud 3: 43-58.

6. Douglas I, Alam K, Maghenda M, Mcdonnell Y, Mclean L et al. (2008) Unjust Waters: Climate change, flooding and the urban poor in Africa. Journal of Environment and Urbanisation 20: 187-205.

7. Etuonovbe AK (2011) The devastating effect of flooding in Nigeria, FIG working week 2011 bridging the gap between cultures, Marrakech, Morocco, 18-22.

8. Oriola $\mathrm{O}$ (1984) Strategies for combating urban flooding in a developing nation: a case study from Ondo. The Environmentalist 14: 57-62.

9. Abah CR (2012) Causes of seasonal flooding in flood plains: A case of Makurdi, Northern Nigeria. Int J Environ Stud 69: 904-912.

10. Ologunorisa TE, Tersoo $\mathrm{T}$ (2006) The changing rainfall pattern and its implication for flood frequency in Makurdi, Northern Nigeria. J Appl Sci Env Manag 10: 97-102.

11. Adelekan IO (2010) Vulnerability of poor urban coastal communities to flooding in Lagos, Nigeria. Journal of Environment and Urbanization 22: $433-450$

12. Ologunorisa TE, Adeyemo A (2005) Public perception of flooding hazard in Niger Delta, Nigeria. The Environmentalist 25: 39-45.

13. Brooks M, Gagnon-Lebrun F, Sauvé C (2005) Prioritizing climate change risks and actions on adaptation: A review of selected institutions, tools, and approaches, Discussion paper Canada.

14. Roberts D (2010) Prioritizing climate change adaptation and local level resilience in Durban, South Africa. Environment and Urbanization 22: 397-413. 
Citation: Unaegbu EU and Baker K (2014) Assessing Community Perception and Attitude towards Flooding in the Lower Benue River Basin, Nigeria. J Earth Sci Clim Change 5: 206. doi:10.4172/2157-7617.1000206

Page 7 of 7

15. Van Aalst M, Nyong T, Osman-Elasha B, Rwabizambuga A (2012) Assessing (and addressing) risk in a changing climate, Red Cross Red Crescent Climate Centre and African Development Bank.

16. Reid GM, Sydenham H (1979) A checklist of lower Benue River fishes and an ichthyogeographical review of the Benue River (West Africa). J Nat Hist 13: 41-67.

17. Ameyan O (1985) Variability of soils developed on migmatites in a part of the middle belt of Nigeria. J Appl Geogr 5: 309-323.

18. Ohunakin OS (2010) Energy utilisation and renewable energy sources in Nigeria. J Engg Appl Sci 5: 171-177.

19. Bigombe B, Khadiagala GM (2003) Major trends affecting families in sub-Saharan Africa: A background document, Report for United Nations Department of Economic and Social Affairs, Division for Social Policy and Development Program on the family.

20. UNISDR (2005) Hyogo framework for action 2005-2015: Building the resilience of nations and communities to disasters.

21. Walker G, Burningham K, Fielding J, Smith G, Thrush D et al. (2006) Addressing environmental inequalities: Flood risk, Environment Agency, Bristol.

22. Adger WN, Brooks N, Bentham G, Agnew M, Eriksen S (2004) New indicators of vulnerability and adaptive capacity, Technical Report 7 ,
Tyndall Centre for Climate Change Research, University of East Anglia, Norwich, UK.

23. Sterling J (2013) Oklahoma tornado: Latest developments, CNN.

24. Palmer J (2014) Oklahoma tornado victims take insurance claims to court, NewsOk.

25. Barnett J, Webber M (2009) Accommodating migration to promote adaptation to climate change, Swedish Commission on Climate Change and Development, Stockholm.

26. Hajat S, Ebi KL, Kovats S, Menne B, Edwards S, et al. (2003) The human health consequences of flooding in Europe and the implications for public health: A review of the evidence. Journal of Applied Environmental Science and Public Health 1: 13-21.

27. Mainlay J, Tan SF (2012) Mainstreaming gender and climate change in Nepal, IIED publication.

28. National Bureau of Statistic (2012) Transportation statistics in Nigeria.

29. Utsev JT, Aho MI (2012) Water shortage and health problems in Benue state-Nigeria: Impacts and prospects for solutions. Int J Sci Tech Res 1: 79-85.

30. National Bureau of Statistics (2009) Social statistics in Nigeria. 